\title{
Wildfires: Opportunity for restoration?
}

Leverkus A.B. [1*], García Murillo P. [2], Jurado Doña V. [3], \& Pausas J.G. [4]

1. Field Station Fabrikschleichach, Department of Animal Ecology and Tropical Biology (Zoology

III), Julius-Maximilians-University Würzburg, 96181 Rauhenebrach, Germany.

2. Departamento de Biología Vegetal y Ecología, Universidad de Sevilla, E-41012 Sevilla, Spain.

3. Departamento de Geografía Física y Análisis Geográfico Regional, Universidad de Sevilla, E41004 Sevilla, Spain.

4. Centro de Investigaciones sobre Desertificación (CIDE-CSIC), 46113 Montcada, Valencia, Spain.

*Corresponding author. Email: alexandro.leverkus@uah.es

The final version of this article is published in Science (2019):

https://doi.org/10.1126/science.aaw2134

Wildfires are increasingly making global headlines due to their destructive effects. In many parts of the world, climate change (1), accelerating land-use alterations (2), and other factors are making large wildfires more frequent and their ecological effects more severe (3). Most organisms in the world's fire-prone ecosystems have evolutionary adaptations to cope with natural fire cycles (2). However, ongoing changes in fire regimes, coupled with drier climate and other associated natural and anthropogenic disturbances (4-6), can surpass the capacity of organisms to cope with disturbance (7) and ultimately trigger ecosystem collapse (5). As a result, wildfires are one of the major drivers of change in forest cover worldwide (8). Yet, under some circumstances, wildfires can also provide an opportunity for ecosystem restoration.

About 2 billion hectares of the world's terrestrial ecosystems are considered degraded and in need of ecological restoration (9), and most ecosystems are under the threat of changing climatic conditions. Wildfires can provide a window of opportunity in which scientists and forest managers can take action to restore degraded ecosystems, eradicate undesirable species and pests, and favor vegetation that is better adapted to future climatic conditions. For example, dense, monospecific pine plantations from the 20th century, which are often unproductive because of climate and soil limitations, abound across the Mediterranean Region (10). They were originally planted to retain soil and regain plant cover, but they now generate many ecological challenges, such as increasing the risk of high-intensity fire and hindering the development of native vegetation (10). Wildfires may thus release the native vegetation from the fierce competition of the dense pine canopy [e.g., (11)] and provide management opportunities to favor more diverse and resilient-and less flammable - communities, including species adapted to future fires and to drier conditions. Such management can involve letting preexistent natural communities, previously oppressed by competitive planted canopies, regenerate on their own through passive restoration, or providing 
some help through population reinforcement. In other cases, postfire restoration could be a time to conduct assisted migration to reduce forest vulnerability to future fire and drought conditions (6). Wildfires generally trigger management actions and attract funding to implement them. Forest managers and scientists should leverage these opportunities to address long-term goals that could not be easily achieved in the absence of wildfires because of public opposition, lack of access through dense vegetation, lack of funding, or too much bureaucracy. Moreover, forest policy should include contingencies for wildfires so that, in case one occurs, appropriate management actions are predefined to address not only the imminently necessary treatments identified during the emergency situation but also mid- and long-term goals.

We do not minimize the problems and risks associated with wildfires, nor do we wish to stimulate the spread of uncontrolled fires with potentially tragic consequences. However, once a wildfire has occurred and the immediate danger has passed, we urge scientists and forest managers to seize the opportunity to rethink forest management and foster more resilient landscapes.

\section{REFERENCES}

1. R. Seidl et al., Nat. Clim. Change 7, 395 (2017).

2. J. G. Pausas, J. E. Keeley, Bioscience 59, 593 (2009).

3. C. I. Millar, N. L. Stephenson, Science 349, 823 (2015).

4. A. B. Leverkus, D. B. Lindenmayer, S. Thorn, L. Gustafsson, Glob. Ecol. Biogeogr. 27, 1140 (2018).

5. D. B. Lindenmayer, C. Sato, Proc. Natl. Acad. Sci. U.S.A. 115, 5181 (2018).

6. C. D. Allen, D. D. Breshears, N. G. McDowell, Ecosphere 6, 1 (2015).

7. J. F. Johnstone et al., Front. Ecol. Environ. 14, 369 (2016).

8. P. G. Curtis, C. M. Slay, N. L. Harris, A. Tyukavina, M. C. Hansen, Science 361, 1108 (2018).

9. R. Cernansky, Nature 560, 542 (2018).

10. J. G. Pausas, S. Fernández-Muñoz, Clim. Change 110, 215 (2012).

11. A. B. Leverkus, J. M. Rey Benayas, J. Castro, Ecology 97, 2628 (2016). 